\title{
Analysis of good practices media education by Mobile applications Odinokaya M. ${ }^{1}$, Lebedev A. ${ }^{2}$ (Russian Federation) Анализ положительных практик организации медиаобразования посредством мобильных приложений
} Одинокая М. А. ${ }^{1}$, Лебедев А. А. ${ }^{2}$ (Российская Федерация)

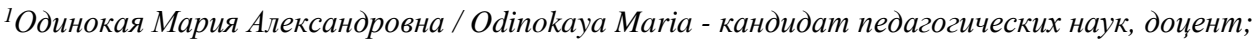 \\ ${ }^{2}$ Лебедев Александр Александрович / Lebedev Aleksander - бакалавр, \\ направление: системный анализ и управление, \\ кафедра системного анализа и управления, \\ Санкт-Петербургский политехнический университет Петра Великого, г. Санкт-Петербург
}

\begin{abstract}
Аннотация: в статье рассматривается дидактический потенциал использования медиаобразовательного контента, предоставляемого для смартфонов, в самостоятельной работе студентов по иностранному языку. Обосновывается актуальность и иелесообразность использования медиаобразовательного контента. Особое внимание уделяется уточнению ключевого понятия «медиаобразование». Проанализированы многочисленные примеры использования существующего медиаобразовательного контента, направленные на овладение иностранным языком. Делается вывод о иелесообразности использования медиаобразовательного контента в проиессе самостоятельного изучения иностранного языка.

Abstract: the article reveals the didactic potential of method of the uasge of media educational content provided for smartphones for students' independent work in the field of foreign language. The author provides guidance of the usage of media educational content. Special attention is given to the specifying the key term «media education». Numerical examples of media educational content usage to learn foreign language are analyzed. In conclusion, it is determined that this technique has great potential for its use in the process of self-study language.
\end{abstract}

Ключевые слова: медиаобразование, мобильные приложения, интерактивность, самообразование. Keywords: media education, mobile apps, interactivity, self-education.

В процессе реформирования и модернизации образования в России растет актуальность проблемы поиска новых технологий и методик образовательных процессов, в частности самообразования. Этим обусловлен интерес разработчиков и исследователей в реализации максимально понятного, доступного и эффективного медиаобразовательного контента.

Современный термин «медиаобразование», представляющий собой дословный перевод термина зарубежной педагогики «MediaEducation», был заимствован в 1986 г. [3]. В настоящее время отсутствует общепринятое определение данного понятия. При обобщении всех имеющихся дефиниций, можно определить термин как процесс развития личности с помощью средств массовой коммуникации с целью формирования культуры общения с медиа, творческих, коммуникативных способностей, критического мышления, умений полноценного восприятия, интерпретации, анализа и оценки медиатекстов, обучения различным формам самовыражения при помощи медиатехники.

В процессе обучения традиционно используются средства медиа, сеть Интернет, блоги, мультимедийные проекты, презентации и др. [2]. В последние годы набирает популярность такое нетрадиционное средство организации самостоятельной работы, как мобильные приложения для изучения иностранных языков. Происходит вытеснение проводной сети Интернет более удобным мобильным Интернетом.

Под мобильным обучением понимается деятельность, осуществляемая регулярно посредством компактных, портативных, мобильных устройств и технологий [5], а в связи с глобализацией и мобилизацией у людей появляется необходимость в быстром и эффективном изучении иностранных языков. В таком случае оптимальным выходом для многих является самообразование путем применения популярных мобильных платформ. Под мобильными устройствами следует понимать смартфоны, коммуникаторы, планшеты, т.е. устройства, работающие под управлением ОС (операционной системы) (например, IOS, Android, Windows Phone и т.д.), которые поддерживают работу в мобильных сетях и технологию Wi-Fi (технология беспроводных сетей).

Приложение для изучения иностранного языка представляет собой, в первую очередь, способ тренировки приобретенных языковых навыков. Это осуществляется благодаря доступу в любом месте и в любое время к разновидным заданиям. Также это отличный источник для расширения лексического запаса, поскольку все современные разработки данного типа включают в себя словарь. Немаловажным фактором является и привлекательный интерфейс с модифицированным представлением информации, который делает сложный образовательный процесс доступным, своевременным и персонализированным, в частности по Дж. Трекслеру [6] «just-in-time», «just enough», «just-for-mе» и др.

В настоящее время разработчики предлагают современному пользователю медиаобразовательный контент на любой вкус. Некоторые приложения имеют более развлекательный характер, они отличаются большим приближением к игре, что способствует, по мнению О. М. Рябцевой [7], формированию устойчивой положительной мотивации. Другие приложения, наоборот, нацелены на более серьезного пользователя. 
Каждый ресурс можно использовать с любым уровнем знания иностранного языка и подбирать для себя наиболее подходящие тематики и учебные задания. Из чего следует вопрос о выборе оптимального приложения из большого количества вариантов.

В ходе исследования были определены наиболее интересные для рассмотрения медиаобразовательные ресурсы. Были выбраны следующие приложения, такие как: LinguaLeo [8], Memrise [9], Duolingo [10], PuzzleEnglish [11] и др., основанные на принципе коротких и легко выполняемых учебных заданий.

Первым рассмотренным сервисом стал LinguaLeo. Служба основана 1 марта 2010 и на данный момент доступна через приложения для $\mathrm{iOS}$, Android и Windows Phone как веб-приложение и расширение для браузеров Google Chrome, Internet Explorer, Mozilla Firefox, Opera и Safari. Были выявлены положительные стороны приложения: возможность изучать слова и фразы, составляя собственный словарь; наличие озвучки и транскрипций в глоссарии; грамматические курсы разного уровня; просмотр контента на английском языке с субтитрами или комментариями (статьи, мультфильмы, отрывки из книг, песни, клипы); огромный выбор тренировок (перевод фраз, мини текстов, аудирование и др.); возможность общаться с другими пользователями pecypca.

Также были выявлены отрицательные стороны, с точки зрения обычного пользователя: ограниченное количество тренировок в день в бесплатной версии; ограниченное пополнение личного словаря в бесплатной версии; доступность не всех грамматических курсов в бесплатной версии; в мобильном приложении более урезанный вариант, в отличие от сервиса из интернета; доступен только английский язык. Отличительными особенностями данного приложения являются: система уровней и заданий; система очков; персонаж Leo.

Memrise - не менее популярная и уникальная онлайн платформа, доступная для веб-приложений, Android платформ и IOS. Возможна развертка приложения из облака, что означает сохранение всей информации в сети Интернет с возможностью восстановления на любом устройстве. Она соединяет в себе три важных компонента: науку о том, как работает мозг; развлечение; собственное сообщество пользователей. К достоинствам этого приложения можно отнести: содержание более 300000 курсов в различных областях, включая курсы иностранных языков; возможность создавать собственные курсы; возможность проходить курсы оффлайн; Mems - необычные способы запоминания слов и фраз (визуальные представления значений новых слов); возможность общаться с другими пользователями и следить за их профилями; просмотр видео, речь на котором от носителей языка. Недостатками, с точки зрения обычного пользователя, являются доступность не всех функций приложения в свободном доступе. Отличительными особенностями данного приложения являются: система очков и поощрений; управляемое тестирование; заданные напоминания.

Duolingo - следующий медиаобразовательный ресурс, появившийся 11 октября 2011 года. Он, как и большинство приложений, доступен на различных платформах: Android, IOS, Windows Phone, a также существует сайт Duolingo, доступный с персонального компьютера. Duolingo - компания, в которую возможно устроиться на работу, сотрудники которой регулярно публикуют научные статьи. Были выявлены положительные стороны приложения: персонализированное обучение; игрофикация обучения; доступность приложения по всему миру; собственная статистика изучения иностранного языка; возможность получить сертификат после обучения; возможность создавать собственные образовательные курсы. Также были выявлены отрицательные стороны, с точки зрения обычного пользователя: различие в функционале на разных платформах; ограничение бесплатного контента; отсутствие озвучки слов (аудирования). Отличительные особенности Duolingo: система подсчета очков; существование языкового инкубатора.

Следующая платформа - PuzzleEnglish. Она доступна с любых компьютеров, мобильных устройств и планшетов. Она включает в себя четыре отдельных приложения: Дуэль (английский, эрудиция), Английский по методу Тичера, Английский с PuzzleEnglish, Английский язык по сериалам. Положительные стороны приложения: более 400 видеоуроков с профессиональными преподавателями по грамматике; «видеопазлы» («сборка» фрагментов фраз для того, чтобы научиться понимать на слух); пополнение словаря с помощью тренировок; «витаминки» (возможность узнать, как говорят на «живом» английском языке); игры; «аудиопазлы» (прослушивание речи носителей языка). Отрицательные стороны, с точки зрения обычного пользователя: ограничение бесплатного контента; ограничение возможностей для бесплатной версии. Отличительными особенностями являются система подсчета очков; аудио- и видеофрагменты из популярных фильмов, сериалов и клипов, привлекательных для пользователя. 


\section{Статистика использования мобильных приложений для изучения иностранного языка}

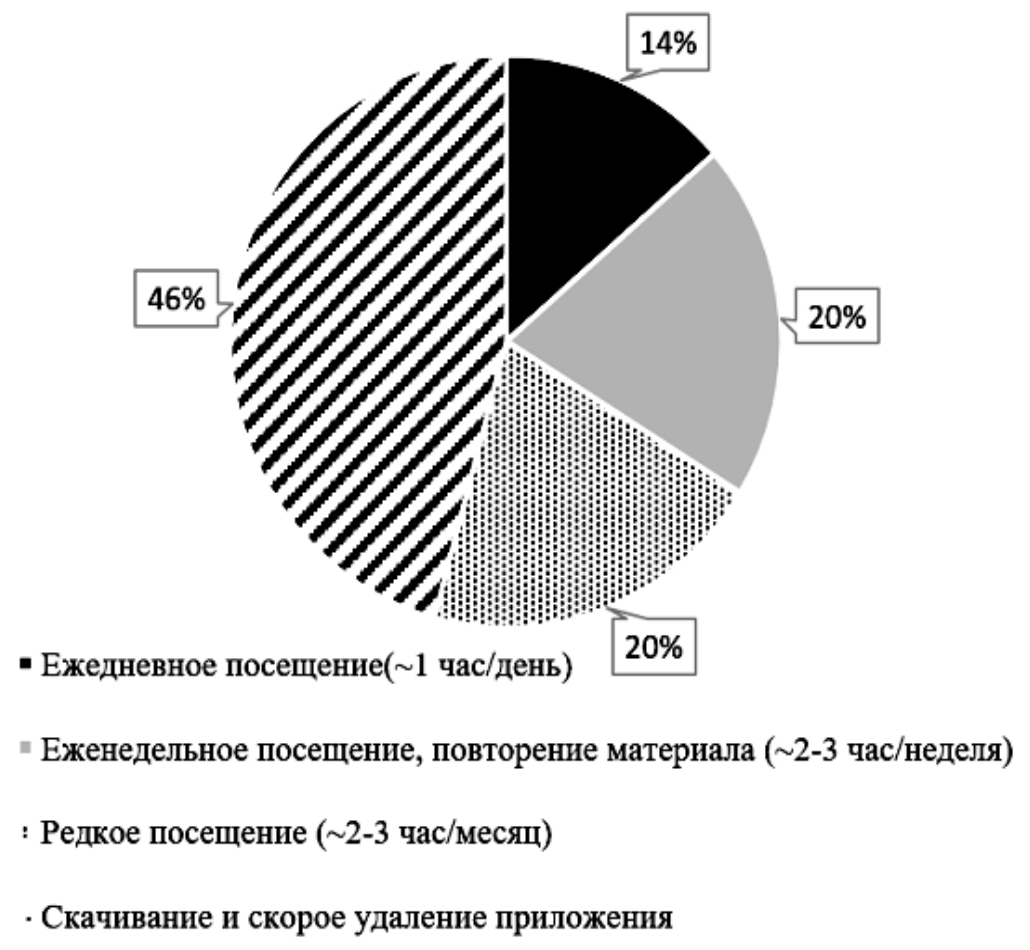

Рис. 1. Осознание респондентов использования мобильных приложений для изучения иностранного языка

Суммируя то, что было сказано, к достоинствам всех вышеперечисленных образовательных платформ можно отнести: систему подсчета очков, наличие бесплатной версии и большой объем образовательного контента. Недостатками всех образовательных платформ является ограничение бесплатного контента и отсутствие возможности прохождения курсов и пополнения словаря, если он присутствует, в режиме оффлайн (без подключения к сети Интернет). Поскольку каждая из платформ обладает индивидуальным функционалом, положительные и отрицательные качества определяются конкретными задачами обучающегося.

Подводя итоги, отметим, что мобильное обучение, основывающееся на принципе управляемого интерактивного самообучения с использованием мобильных приложений, обладает широкими возможностями для активизации и интенсификации самостоятельной деятельности студентов. Проведенный анализ использования мобильных приложений для изучения иностранного языка (Рис. 1) показывает, что немаловажным фактором самообразования является мотивация. Согласно проведенному опросу, почти половина (46\%) пользователей отказываются от использования мобильных образовательных платформ, теряя интерес к ним. По мнению Дж. Трекера, Ю.В.Еремина, только ежедневное использование подобных образовательных сервисов является оптимальным для изучающих иностранные языки, поэтому лишь $14 \%$ опрошенных эффективно изучают иностранный язык посредством мобильных образовательных платформ. В то время как остальные респонденты поддерживают свои лингвистические навыки на прежнем уровне.

\section{Лumepamypa}

1. Михалева Г. В. Модель современного медиаобразования в Великобритании // Всероссийский журнал научных публикаций, 2011. № 9 (10). С. 118-119.

2. Хльзова Н. Ю. Медиаобразование в обучении межкультурной коммуникации // MagisterDixit., 2012. № 2. C. 95.

3. Хлызова Н. Ю. Медиаобразование и медиакомпетентность в эпоху информационного общества// Вестн. Том. гос. ун-та, 2011. № 342. С. 188.

4. [Электронный ресурc]: rb.ru. 2016. Режим доступа: http://rb.ru/news/lingualeo-10-mln/ (дата обращения: 20.10.2016).

5. Еремин Ю. В., Крылова Е. А. Использование мобильных технологий в самостоятельной работе студентов по иностранному языку в неязыковом вузе // Известия РГПУ им. А. И. Герцена, 2014. № 167. С. 159-163.

6. Traxler J. Current state of mobile learning // Mobile learning: Transforming the delivery of education and training. [Электронный ресурс]. 2009 (дата обращения: 12.12.2016).

7. Рябцева О. М. Пути повышения мотивации в изучении иностранного языка // Известия ЮФУ. Технические науки, 2012. № 10. 
8. [Электронный pecypc]: lingualeo.com. 2016. Режим доступа: https://lingualeo.com/ru/ (дата обращения: 22.10.2016).

9. [Электронный pecypc]: memrise.com. 2016. Режим доступа: https://www.memrise.com/ (дата обращения: 22.10.2016).

10. [Электронный pecypc]: duolingo.com. 2016. Режим доступа: www.duolingo.com (дата обращения: 22.10.2016).

11. [Электронный pecypc]: puzzle-english.com. 2016. Режим доступа: https://puzzle-english.com/ (дата обращения: 22.10.2016). 